Meta

Journal des traducteurs

Translators' Journal

\title{
The Brief Wondrous Life of Oscar Wao de Junot Díaz en lenguas escandinavas
}

\section{Åse Johnsen}

Volume 64, numéro 3, décembre 2019

URI : https://id.erudit.org/iderudit/1070530ar

DOI : https://doi.org/10.7202/1070530ar

Aller au sommaire du numéro

Éditeur(s)

Les Presses de l’Université de Montréal

ISSN

0026-0452 (imprimé)

1492-1421 (numérique)

Découvrir la revue

Citer cet article

Johnsen, Å. (2019). The Brief Wondrous Life of Oscar Wao de Junot Díaz en lenguas escandinavas. Meta, 64(3), 580-599. https://doi.org/10.7202/1070530ar
Résumé de l'article

Pour les traducteurs, la présence d'éléments dans une ou plusieurs langues étrangères dans un texte littéraire représente un défi particulier. Le traducteur doit opérer des choix en matière de méthode et de stratégies de traduction : ces éléments doivent-ils être transférés tels quels, se traduire ou être expliqués ? Dans cet article, sont présentées les traductions dans trois langues scandinaves, danois, norvégien et suédois, de l'une des oeuvres les plus connues de l'auteur dominicain-américain Junot Díaz, The Brief Wondrous Life of Oscar Wao. Cette étude comparative présente un cas intéressant dans la mesure où les trois pays scandinaves en question se ressemblent aussi bien du point de vue linguistique que du point de vue socioculturel. Malgré ces similitudes, les traducteurs de ce roman ont adopté des approches très différentes lorsqu'il s'agit de traduire les éléments en langue étrangère dans le texte original.
Ce document est protégé par la loi sur le droit d'auteur. L'utilisation des services d’Érudit (y compris la reproduction) est assujettie à sa politique d'utilisation que vous pouvez consulter en ligne.

https://apropos.erudit.org/fr/usagers/politique-dutilisation/ 


\title{
The Brief Wondrous Life of Oscar Wao de Junot Díaz en lenguas escandinavas
}

\author{
ÅSE JOHNSEN \\ Universitetet i Bergen, Bergen, Noruega \\ ase.johnsen@uib.no
}

\section{RÉSUMÉ}

Pour les traducteurs, la présence d'éléments dans une ou plusieurs langues étrangères dans un texte littéraire représente un défi particulier. Le traducteur doit opérer des choix en matière de méthode et de stratégies de traduction: ces éléments doivent-ils être transférés tels quels, se traduire ou être expliqués? Dans cet article, sont présentées les traductions dans trois langues scandinaves, danois, norvégien et suédois, de l'une des œuvres les plus connues de l'auteur dominicain-américain Junot Díaz, The BriefWondrous Life of Oscar Wao. Cette étude comparative présente un cas intéressant dans la mesure où les trois pays scandinaves en question se ressemblent aussi bien du point de vue linguistique que du point de vue socioculturel. Malgré ces similitudes, les traducteurs de ce roman ont adopté des approches très différentes lorsqu'il s'agit de traduire les éléments en langue étrangère dans le texte original.

\section{ABSTRACT}

For translators, text passages in one or several foreign languages in a literary work are particularly challenging. Translators must make choices with regard to both method and translation strategies when dealing with such passages in the source text: are they to be transferred, translated or explained? This article studies the translation of one of the most famous novels written by the Dominican-American author Junot Díaz, The BriefWondrous Life of Oscar Wao, and its translations to three Scandinavian languages: Danish, Norwegian and Swedish. This comparative study of translations constitutes an interesting case, as both the languages and sociocultural settings in the three countries are similar. Notwithstanding, this study shows the translators of the novel have chosen very different approaches when they translate the shift between the languages in the original text.

\section{RESUMEN}

Para los traductores, el bilingüismo o multilingüismo en una obra literaria supone un desafío añadido en su trabajo de verter un texto de una lengua a otra. Al tratar los elementos extranjeros del texto original, los traductores tienen que elegir entre varios métodos y estrategias, entre ellas, transferirlos, traducirlos o explicarlos. En el presente trabajo estudiaremos la traducción de una de las novelas más conocidas del escritor estadounidense de origen dominicano Junot Díaz, The Brief Wondrous Life of Oscar Wao, y las traducciones a las tres lenguas escandinavas: danés, noruego y sueco. El estudio comparativo de traducciones a las lenguas escandinavas constituye un caso interesante, puesto que tanto las lenguas como la realidad sociocultural de los tres países se parecen. No obstante, tal como muestra el presente estudio, los traductores de la obra han elegido métodos muy diferentes al traducir la alternancia entre lenguas en el original.

\section{MOTS-CLÉS/KEYWORDS/PALABRAS CLAVE}

traduction littéraire, littérature multilingue, méthode de traduction, langues scandinaves, Junot Díaz 
literary translation, multilingual literature, translation method, Scandinavian languages, Junot Díaz

traducción literaria, literatura multilingüe, método de traducción, lenguas escandinavas, Junot Díaz

Para Marius Hjelle, in memoriam

\section{Introducción}

En una entrevista con el diario español El Mundo, el escritor estadounidense de origen dominicano Junot Díaz comenta que «Todos mis sueños son bilingües» ${ }^{1}$ y ese bilingüismo de sus sueños se refleja también en sus obras. Díaz vive en EE. UU. y escribe sus obras en un inglés salpicado con palabras y oraciones tanto en su lengua materna, español, como en otras lenguas. De modo que sus obras son en realidad multilingües, aunque la alternancia inglés-español es la más frecuente y es también un reflejo de la realidad sociocultural en la que vive Díaz en EE. UU. En el presente trabajo estudiaremos una de sus novelas más conocidas: The Brief Wondrous Life of Oscar $W_{a o^{2}}(B W L O W)$, y las traducciones a las tres lenguas escandinavas: danés, noruego y sueco. Queremos dejar constancia de que nuestro análisis no pretende hacer una evaluación de las traducciones, calificándolas como buenas o malas, sino describir los métodos de traducción que se han elegido en cada una de ellas. El estudio comparativo de traducciones a las lenguas escandinavas constituye un caso interesante, puesto que tanto las lenguas como la realidad sociocultural de los tres países se parecen. No obstante, se ve en el presente estudio que las tres traducciones de la obra presentan soluciones muy diferentes al tratar los elementos en español del original.

\section{El multilingüismo}

El multilingüismo, o cambio de códigos lingüísticos, en este artículo se refiere a la presencia de dos o más lenguas en un mismo discurso o texto. Esta mezcla de lenguas puede manifestarse de dos formas principales: dentro de una misma oración, o sea, de modo intraoracional, o entre oraciones o partes de texto, es decir, de modo interoracional. ${ }^{3}$ La presencia simultánea de dos o más lenguas es cada vez más visible en nuestro mundo globalizado. A causa de la migración, voluntaria o no, nuestras sociedades se convierten cada vez en más multilingües y multiculturales. Como ejemplo se puede mencionar que, en un país pequeño como Noruega, con cinco millones de habitantes, el grupo de inmigrantes representa más de 150 lenguas ${ }^{4}$. En su artículo «Fictional representations of multilingualism and translation» de 2005, señalan Delabastita y Grutman que «[in] today's world, talk of multilingualism no longer raises eyebrows but is seen, quite matter-of-factly, as a sign of the times» (2005: 11).

\subsection{El multilingüismo en la literatura}

El hecho de que nuestras sociedades cada vez sean más multilingües se refleja también en la literatura. Muchos escritores viven en ciudades cosmopolitas rodeados de varias culturas y lenguas o son migrantes que viven y trabajan entre dos o varias lenguas y culturas. Sin embargo, los textos literarios multilingües no son un fenómeno nuevo: 
Delabastita y Grutman (2005: 16-17) señalan dos conocidos ejemplos de la literatura hispana. El primero es la novela Tres tristes tigres de Cabrera Infante (1965), en cuyo prólogo alternan el español cubano con el inglés para dar una imagen de la vida nocturna en La Habana de la década de 1950. El segundo ejemplo es la obra de Goytisolo Juan sin tierra (1975), en la que el español estándar se convierte en español cubano para luego convertirse en una variante de la lengua árabe y terminar con versos árabes escritos en caligrafía. Puesto que el árabe se lee de derecha a izquierda, el final árabe de la obra constituye también un nuevo comienzo de lectura del texto. En estos dos ejemplos el multilingüismo tiene funciones distintas, en el ejemplo de Cabrera Infante, se usa el cambio de código lingüístico entre otras cosas para caracterizar a los personajes y crear diferentes ambientes y, de esa manera, mostrar la presencia de los norteamericanos en Cuba en los años 1950, mientras que en el de Goytisolo se trata sobre todo de un recurso literario estilístico.

En el caso de Díaz, el uso del multilingüismo refleja, en primer lugar, la realidad multilingüe y multicultural en la que vive el autor. Según Munday, el fenómeno del multilingüismo es frecuente en escritores que publican en Estados Unidos: «A whole new hybrid form of writing has come from Latinos living in the United States [...], writing in English but displaying their roots through the Latin themes and the syntactic or lexical influence of Spanish» (Munday 2007: 61). Tal como señala Munday, la lengua base de estos escritores es el inglés, mientras que el español aparece en el léxico y en la sintaxis. Este uso de cambio de código, por consiguiente, no es lo mismo que el spanglish que suele tener como base el español:

[g]eneralmente, cuando se habla de spanglish, se piensa en un discurso con base española, salpicado de elementos de la lengua inglesa, «adaptados» al español («llamar para atrás» en lugar de to call back [...], por ejemplo). De hecho, parece que el término en sí mismo intensifica y da prioridad a la lengua española sobre la inglesa (span-). (Jiménez Carra 2011: 161)

Díaz mismo subraya que la lengua de su obra no es spanglish: «Lo que yo escribo no es esa cosa desaliñada que llaman spanglish sino una especie de criollo, con palabras y expresiones intercaladas de español» ${ }^{5}$.

En un estudio sobre el cambio de código inglés - español en novelas publicadas en EE. UU., Montes-Alcalá concluye que el cambio de código es de suma importancia para la literatura escrita por latinos en EE. UU.: «Be it an aesthetic device or a characterization technique, switching languages serves a wide array of socio-pragmatic and stylistic purposes and it plays a crucial role in contemporary US-Latino literature» (Montes-Alcalá 2012: 85-86). La autora explica además que el cambio de código en la literatura estadounidense está ganando legitimidad y el hecho de que Díaz ganara el premio Pulitzer por la novela $B W L O W$ es una prueba de ello (MontesAlcalá 2012: 68).

Aunque el multilingüismo en la era poscolonial globalizada es un reflejo de la realidad lingüística en la que vivimos, el cambio de código lingüístico en un texto literario puede tener tanto funciones lingüísticas como literarias. Delabastita y Grutman proponen una serie de principios básicos narratológicos que pueden hacer uso del multilingüismo:

[w] do want to suggest that the use of multilingualism and interlinguistic situations is perfectly consistent with a number of basic narrative principles, such as conflict, 
character configuration, spatial opposition, mimesis, and suspense management. In other words, the 'emplotment' of multilingualism and translation definitely belongs to the intrinsic potentialities of the narrative genre. (Delabastita y Grutman 2005: 24)

Montes-Alcalá señala que el uso del cambio de código en la literatura «may obey stylistic or aesthetic rules and it can also be used as a source of credibility and/or to communicate biculturalism, humor, criticism and ethnicity» (Montes-Alcalá 2012: 69).

Por otro lado, en un artículo sobre el cambio de código en la narrativa chicana, García Vizcaíno señala varias funciones lingüísticas que ha encontrado en tres novelas de la escritora chicana Sandra Cisneros. Esta escritora escribe en inglés, pero usa el español para poner de relieve algunos aspectos de las novelas, sea para crear un efecto dramático e incluso cómico, o sea para poner énfasis en los actos de habla. García Vizcaíno encuentra ejemplos de cambio de código de cuatro de los actos de habla de Searle en las novelas estudiadas: directivos, compromisivos, expresivos y declarativos. Además, encuentra que Cisneros cambia al español cuando trata temas como la familia o la religión, reforzando de esa manera el contenido proposicional de la oración (García Vizcaíno 2008: 213-215).

Jonsson analiza en un estudio el multilingüismo en dos novelas suecas en las que frecuentemente aparecen elementos de las lenguas sami o finlandesa, lenguas minoritarias en Suecia. Ella concluye que:

[t]hrough the texts, silenced voices such as those of minority language speakers are given space to be heard. As stated by the authors in my interviews, this can have empowering functions for the speakers and for communities as such. Silenced voices are thus legitimized through their use in novels. (Jonsson 2012: 228)

El multilingüismo en la literatura puede, por consiguiente, tener funciones tanto literarias como lingüísticas. Además, puede tener su origen en factores extralingüísticos/extraliterarios como «la localización geográfica, razones políticas o la afirmación de la propia identidad» (Jiménez Carra 2011: 162), es decir, puede ser un reflejo de la realidad multilingüe del mundo globalizado que rodea a los escritores que producen los textos bilingües o multilingües. Como veremos a continuación, para Díaz el uso de la mezcla de lenguas también tiene una función política.

\subsection{El multilingüismo en la novela BWLOW}

La obra objeto del presente análisis fue publicada en el año 2007 y el año siguiente recibió el prestigioso Premio Pulitzer de Novela. La novela trata la historia de tres generaciones de la familia dominicana de los Cabral. La trama de la novela se desarrolla en Nueva Jersey, en el ambiente de los inmigrantes dominicanos, y en la República Dominicana, donde vive parte de la familia Cabral. La alternancia entre el inglés americano y el español refleja, por consiguiente, el espacio geográfico de la República Dominicana y la realidad bilingüe que viven los inmigrantes dominicanos (y otros hispanoamericanos) en EE. UU.

Jiménez Carra (2011: 168-170) identifica varios usos y estrategias de la alternancia español-inglés en la obra $B W L O W$, algunas de las cuales se pueden resumir como sigue:

- el uso del español cuando se trata de determinados contextos familiares y coloquiales

- el empleo del español con o sin explicaciones en inglés

- el uso de elementos hispanos con o sin presencia del idioma español 
- el no distinguir entre el español y el inglés ortográficamente (por ejemplo, mediante cursiva)

- la omisión de elementos gramaticales o tipográficos tanto en español como en inglés

- el uso de estructuras gramaticales españolas en el idioma inglés

Finalmente menciona otra característica de la obra: «el frecuente uso de notas a pie de página para situar al lector en el contexto histórico de ciertas referencias culturales» (2011: 169).

En la mayoría de los casos, Díaz no explica ni traduce las partes que escribe en español, de manera que el lector monolingüe entra en el mundo de los inmigrantes tal como lo describe Boyden y Goethals: «As a result the reader gets the impression of being pulled into the bilingual dynamic of the immigrant community, without necessarily understanding everything that is going on between the interlocutors» (2001: 22).

El lector, por consiguiente, es testigo de una experiencia más bien auténtica del uso de las lenguas en una comunidad bilingüe. En una entrevista, Díaz explica el uso de las lenguas en sus obras ${ }^{5}$ como un acto político con referencia a las lenguas minoritarias y las dominantes:

[a]lso for me, allowing the Spanish to exist in my text without the benefit of italics or quotation marks was a very important political move. Spanish is not a minority language. Not in this hemisphere, not in the United States, not in the world inside my head. So why treat it like one? Why 'other' it? Why denormalize it? By keeping the Spanish as normative in a predominantly English text, I wanted to remind readers of the fluidity of languages, the mutability of languages. And to mark how steadily English is transforming Spanish and Spanish is transforming English. [...] When I learned English in the States, this was a violent experience. And by forcing Spanish back into English, forcing it to deal with the language it tried to exterminate in me, I've tried to represent a mirror-image of that violence on the page. Call it my revenge on English. (Céspedes, Torres-Saillant y Díaz 2000: 904)

Otro motivo de crear textos bilingües inglés-español es, según Díaz, adelantar el proceso de la introducción de palabras españolas en la lengua inglesa: «I decided I don't need 100 years for the Oxford English Dictionary to tell me that it's o.k. to adopt this or that word as part of our normal vocabulary. I feel that's what we always should do. We should be pushing the dates on words» (Céspedes, Torres-Saillant y Díaz 2000: 904).

No obstante, independientemente de los motivos del autor, las partes en español no traducidas o no explicadas pueden causar frustración entre los lectores que no dominan ambas lenguas, hasta tal punto que dejen de leer el texto. En las reseñas de lectores se pueden encontrar reacciones de los lectores. A continuación, citamos del foro de lectores de Amazon.com:

[b]e patient, it warms up, February 3, 2008

By D. Kanigan

This review is from: The Brief Wondrous Life of Oscar Wao (Hardcover)

The first half of the book was challenging to read as the author uses footnotes and many Spanish language phrases that are not translated [...]. These language challenges, coupled with the weaving back and forth from the present to the past and between multiple characters made the storyline challenging to follow and impacted my enjoyment of the story. [...] Hang in there as the book warms up at p. 150 and beyond where the main characters develop very nicely. 
$[\ldots]$

Marzipanned says:

[...]

Well, maybe I'll give it a try. I got so frustrated last night (around page 120) that I threw it across the room. The untranslated Spanish is insulting to the reader. The footnotes get more and more boring as I go along. I've been hoping to get back to Oscar but I keep wading through stories about the sex lives of his sister and mother. Enough already. ${ }^{6}$

Como se ve en estas citas, las partes en español causan frustraciones entre algunos lectores puesto que no entienden los elementos en español intercalados en el texto inglés. Para ayudarse entre ellos, algunos lectores han puesto páginas en Internet con glosarios alfabéticos ${ }^{7}$ o con explicaciones de palabras y expresiones culturales, capítulo por capítulo ${ }^{8}$.

El uso de dos o más lenguas puede, no obstante, complacer al lector. Torres, que ha hecho un estudio del uso del cambio de código lingüístico inglés-español en textos publicados entre 1994 y 2004 por escritores de origen latinoamericano que viven y trabajan en EE. UU., encuentra cuatro estrategias que usan los escritores. Dos de las estrategias tienen como resultado complacer al lector monolingüe y dos al lector bilingüe. Las estrategias que complacen al lector monolingüe son el uso de palabras españoles conocidas o la traducción. Al respecto señala:

[i]n some texts, few Spanish words occur and most (except the most obvious) are translated for the reader. Writers may desire to mark the text as Latino/a at the linguistic level but may not wish to alienate monolingual English readers. [...] In some Latino/a texts, a glossary at the end of the books provides further assurances that the monolingual reader does not have to languish in unfamiliar territory. In these texts, authors give primacy to their monolingual readers. (Torres 2007: 79-82)

Las otras dos estrategias -palabras españolas no traducidas y calco lingüísticotienen como fin complacer al lector bilingüe, aunque a la vez pueden causar frustración entre los lectores monolingües. Sobre ellas dice: «These strategies subvert the commodification of Spanish and gratify the bilingual, bicultural reader» (Torres 2007: 78). Según Torres (2007: 83), los textos de Díaz pertenecen a este último grupo.

La aceptación o no de un texto multilingüe depende por tanto del conocimiento o familiaridad con las lenguas por parte de los lectores, pero también tiene importancia la cantidad de elementos de lengua extranjera. Según la traductora Achy Obejas, la presencia de palabras españolas en la novela $B W L O W$ corresponde a un $18 \%$ del texto. ${ }^{9}$

\section{La traducción de BWLOW}

Igual que el multilingüismo en la obra puede requerir un esfuerzo extra del lector, también supone un desafío adicional para el traductor. En esta parte consideramos primero algunos aspectos de las traducciones al español de $B W L O W$ para luego pasar a las traducciones a las lenguas escandinavas. 


\subsection{La traducción de BWLOW al español}

La traducción de una obra multilingüe es un desafío para el traductor y aún más si se traduce a una de las lenguas que constituyen el original. En cuanto a BWLOW, existen dos traducciones al español: una versión publicada por Mondadori dirigida al mercado español y latinoamericano y una versión de Vintage pensada para el mercado estadounidense. Estas traducciones se analizan en dos artículos publicados en 2011: Jiménez Carra (2011) trata la traducción al español de Mondadori, mientras que Boyden y Goethals (2011) comparan las traducciones de Mondadori y Vintage. Ambas versiones están traducidas por la escritora cubana Achy Obejas.

Jiménez Carra encuentra que en la traducción de Mondadori el cambio de código existente en el texto original (TO) desaparece en la versión española, pero que en algunas ocasiones la traductora compensa con el cambio de código en otros lugares del texto:

[a]ñadiendo un cambio de código similar al encontrado en el TO, pero sin llegar a modificar el significado ni la esencia de la versión original. Ese «inglés que suena a español» se convierte a veces en la traducción en «español que suena a inglés». (Jiménez Carra 2011: 177)

La comparación que hacen Boyden y Goethals entre las dos versiones de la obra traducida al español revela también que el multilingüismo presente en el original se ha reducido hasta cierto punto. Por otra parte, señalan que la relación entre el narrador y el narratario está menos especificada en las traducciones: «It is true that the I's and you's of the translation are underspecified in relation to the original, thus confirming the view that complex narrative voices are simplified in translation (Taivalkoski 2002, quoted in Chesterman 2004)» (Boyden y Goethals 2011: 38). Estos autores encuentran también que el tono racial y sexual en el original frecuentemente se pierde en las traducciones (2011: 37). Señalan, además, que la traductora en muchas ocasiones introduce elementos caribeños o dominicanos en las versiones en español, caracterizando de esa manera a Díaz como un escritor típicamente caribeño o dominicano (2011: 39). En cuanto a las diferencias entre las dos versiones españolas, apuntan:

[w]hile Mondadori brings Díaz's bestseller within the orbit of Spanish literary traditions, the Vintage edition has exported the author back to the North American context, which apparently required the insertion of an extensive footnote apparatus, explaining cultural references from both the U.S. and Dominican culture. Quite ironically, therefore, the Vintage volume constructs an implied reader who is ignorant of the fluid, bilingual cultural background out of which Díaz's novel emerged and which constitutes the shared heritage of a majority of Spanish-language speakers in the U.S. (Boyden y Goethals 2011: 39)

Conviene mencionar que la edición de Vintage ha añadido 115 notas a pie de página a las 33 notas que se encuentran en el original.

En una entrevista en $E l$ País $^{10}$, Díaz se pronuncia sobre la traducción española y dice que le ha gustado: "A mí me gustó, si no, estaría escondido en mi casa». Díaz también reconoce que algo se pierde y algo se gana en la traducción: «La traductora (Achy Obejas) hizo un buen trabajo. Pero hay un precio que pagar por traducir, tienes que perder alguna cosa». En cuanto a la alternancia entre el español y el inglés, apunta: 
[e]n la versión original hay una confrontación de lucha libre entre el inglés y el español. Hasta cuando se lee la parte en inglés se escucha el español porque las estructuras de las oraciones son bien raras, hay un tono y un ritmo caribeño. Creo que cuando se traduce totalmente al español pierde ese conflicto, esa energía, pero gana una enorme cantidad de intimidad, porque el español es un idioma muy íntimo y brutal, y pienso que la brutalidad interna de la familia salió más fuerte en la versión española. ${ }^{11}$

La traducción al español de la obra ha sido un desafío para la traductora Obejas, quien se ha valido de varias estrategias tomando en cuenta los dos grupos de lectores de las dos versiones al español. En lo que sigue, veremos cómo han solucionado los traductores escandinavos el desafío del multilingüismo de la obra.

\subsection{La traducción de BWLOW a las lenguas escandinavas}

Tal como hemos señalado, la familiaridad con las lenguas por parte de los receptores juega un papel importante al decidir cómo se traducen los elementos escritos en otras lenguas distintas a la lengua principal. A los lectores escandinavos no les causa ningún problema que haya partes de inglés en un texto traducido a sus lenguas. El español, sin embargo, a pesar de ser una lengua conocida por muchos, está lejos de tener el mismo estatus que el inglés. No obstante, en los últimos años hay más presencia del español en novelas escritas en las lenguas escandinavas o traducidas a ellas, sobre todo si la trama de la novela se desarrolla en un lugar hispanohablante. ${ }^{12}$ Aun así, la presencia de español en una obra literaria puede causar problemas de comprensión, por lo menos para los lectores adultos. Los jóvenes, por otra parte, están más en contacto con el español, sobre todo mediante la cultura popular (en su mayoría proveniente de EE. UU.). En el caso de Noruega, por ejemplo, muchos jóvenes aprenden español, puesto que a partir de 2006 el español se ha convertido en la lengua extranjera de más difusión en las escuelas del país.

La novela $B W L O W$ se publicó en las lenguas escandinavas en 2009: la traducción danesa es de Niels Lyngs $\varnothing^{13}$; la noruega, de Hege Hammer y Henning Hagerup ${ }^{14}$; y la sueca, de Niclas $\mathrm{Hval}^{15}$. Tal como veremos en el análisis que sigue, las traducciones tratan de manera muy diferente la alternancia entre el inglés y el español. Hemos dividido nuestro análisis en dos partes: En la primera se da una presentación general de las traducciones y el método general elegido por los traductores para tratar los elementos escritos en español (nivel macrotextual). En la segunda parte, se hace un análisis comparativo más detallado de la primera parte del texto, en el que se comparan las tres traducciones en lo que a los elementos españoles y sus funciones en la obra se refiere (nivel microtextual).

\subsubsection{Nivel macrotextual}

A nivel macrotextual se percibe fácilmente el método utilizado por los traductores al danés y al noruego, ya que se ve en los paratextos de la novela. La versión danesa tiene un glosario de cinco páginas ordenado alfabéticamente y, tal como veremos en la segunda parte del análisis, mantiene gran parte de los elementos en español del original, ayudando al lector en su lectura mediante el glosario. En el glosario se traducen al danés palabras del español, como en: 
1) Madre: mor [madre]

(Díaz 2007b/2010: 350, traducido por Niels Lyngsø)

2) Imbécil: idiot [idiota]

(Díaz 2007b/2010: 350, traducido por Niels Lyngsø)

Pero, igualmente, se traducen expresiones u oraciones enteras, como en:

3) No te preocupes. Te traigo: Bare rolig. Jeg kører dig.

[Tranquilo. Te llevo/traigo.]

(Díaz 2007b/2010: 351, traducido por Niels Lyngsø)

Y también se dan algunas explicaciones de tipo cultural o histórico:

4) Moncadistas: Fidel Castro m.fl. indledte et mislykket angrep på Moncadabarakkerne i Havanna, Cuba i 1953, men blev anholdt og fængslet.

[Fidel Castro y otros iniciaron un ataque frustrado al cuartel Moncada, en Cuba, en 1953, pero fueron detenidos y encarcelados.]

(Díaz 2007b/2010: 351, traducido por Niels Lyngsø)

5) Guanábana: sød frugt

[fruto dulce]

(Díaz 2007b/2010: 350, traducido por Niels Lyngsø)

6) Ciguapa: nymfe; væsen fra den dominikanske mytologi

[ninfa; ser de la mitología dominicana]

(Díaz 2007b/2010: 350, traducido por Niels Lyngsø)

A veces resulta difícil encontrar las explicaciones en el glosario, puesto que una expresión como muchacha del diablo, por ejemplo, se encuentra listada bajo diablo y no bajo muchacha (Díaz 2007b/2010: 249, traducido por Niels Lyngsø). Las palabras que aparecen en el glosario no están marcadas en el texto, de manera que es el lector quien tiene que buscar las palabras desconocidas en el glosario. Los críticos daneses elogian al traductor Lyngsø por su trabajo: Per Krogh Hansen ${ }^{16}$, por ejemplo, dice que Lyngsø ha logrado traducir la novela dominicana-americana a «domini-danés» con éxito. También elogia el glosario, que le parece muy informativo.

En cuanto a la traducción noruega, ésta no tiene un glosario, pero tiene 55 notas finales en las que no sólo se presentan traducciones o explicaciones lingüísticas, sino también referencias culturales. Los traductores no se limitan a explicar las referencias a la cultura hispana o dominicana, sino también referencias a otras culturas, como la estadounidense y la japonesa, además de referencias intertextuales literarias. En el texto, las palabras o expresiones explicadas llevan números romanos como referencia a las notas finales, a diferencia de las notas a pie de página introducidas por el autor mismo, que se marcan con números latinos. Podemos mencionar a continuación algunos ejemplos de las notas de los traductores noruegos.

El narrador dice de su amiga Maritza que tiene «energía Ogún» (Díaz 2007a: 14) y en la nota final III los traductores noruegos explican Ogún de la siguiente manera:

7) En av gudene i den kubanske Santería-religionen. (O.a.)

[Uno de los dioses de la religión Santería cubana. (N. del T.)]

(Díaz 2007c/2010: 308, traducido por Hege Hammer y Henning Hagerup) 
El autor se refiere al Phantom Zone sin explicar lo que es (Díaz 2007a: 84), y los traductores al noruego lo traducen literalmente como Fantomsonen (Díaz 2007c/2010: 85, traducido por Hege Hammer y Henning Hagerup) añadiendo una nota final:

8) I Supermann er dette en spøkelsesaktig annen dimensjon, et slags fengsel for de verste forbryterne.(O.a.).

[En Superman esta es una segunda dimensión fantasmal, una especie de cárcel para los peores criminales. (N. del T.)]

(Díaz 2007c/2010: 309, traducido por Hege Hammer y Henning Hagerup)

Conviene mencionar que estas explicaciones también se encuentran en la versión española pensada para el mercado de EE. UU. En los siguientes ejemplos, los traductores noruegos explican referencias a la cultura o lengua japonesas:

9) Otaku: japansk nerd. (O.a.)

[nerdo japonés. (N. del T.)]

(Díaz 2007c/2010: 309, traducido por Hege Hammer y Henning Hagerup)

10) Gaijin: Utlending på japansk, (O.a.)

[Extranjero en japonés. (N. del T.)]

(Díaz 2007c/2010: 308, traducido por Hege Hammer y Henning Hagerup)

De estas dos palabras japonesas, la del ejemplo diez se encuentra también en el glosario danés (Díaz 2007b/2010: 349, traducido por Niels Lyngsø).

En el análisis a nivel microtextual, veremos que la versión noruega es la que más traducciones hace de las partes españolas de la novela. Una reseña de la novela en el periódico noruego Morgenbladet, publicada antes de que se hubiera publicado la traducción, señala que la novela probablemente se lee mejor en versión original, justamente por el cambio de código lingüístico: «[...] pero la llamativa lengua en la novela, entre spanglish, lenguaje de juegos de rol y rap, es probablemente preferible leerla en la versión original $»^{17}$ (nuestra traducción) ${ }^{18}$.

La versión sueca (Díaz 2007d/2010, traducido por Niclas Hval), en cambio, no tiene ningún paratexto que explique ni lengua ni cultura a los lectores y hay que mirar las estrategias a nivel microtextual para encontrar su método general. Como veremos en la segunda parte del análisis, la versión sueca transfiere la mayor parte de los elementos hispanos intercalados en el inglés original.

En este análisis hemos encontrado tres métodos macrotextuales para la traducción de elementos en lengua extranjera: añadir un glosario, añadir notas finales y no añadir nada. En la segunda parte del análisis, relacionamos estos métodos a nivel macrotextual con las estrategias a nivel microtextual elegidas al verter los elementos en lengua española a las lenguas escandinavas.

\subsubsection{Nivel microtextual}

Para hacer un análisis a nivel microtextual, estudiaremos más detenidamente las traducciones de la primera parte de la novela, titulada «GhettoNerd at the End of the World» (Díaz 2007a: 11-50).

Sin embargo, antes de comenzar el análisis de toda la primera parte, conviene analizar un párrafo para ver los elementos en español en un contexto más amplio. Comenzamos, por consiguiente, analizando un párrafo en el que se encuentran nueve 
elementos en español. El objetivo de analizar este párrafo es mostrar cómo se manifiesta el método general preferido por los traductores en la elección de estrategias a nivel microtextual. El contexto es que el tío Rudolfo le da consejos a Oscar, quien no tiene éxito ni experiencia con las mujeres. A continuación presentamos el párrafo del texto original y las tres traducciones de este párrafo con nuestras traducciones al español entre corchetes.

11) Listen, palomo: you have to grab a muchacha, y metéselo! That will take care of everything. Start with a fea. Coje [sic] that fea y metéselo! Tío Rudolfo had four kids with three different women so the nigger was without doubt the family's resident metéselo expert.

(Díaz 2007a: 24)

a) Hør her, palomo: Du er nødt til at få fat i en muchacha, y metéselo! Tío Rudolfo havde fire børn med tre forskellige kvinder, så stodderen var utvilsomt familiens regerende metéselo-ekspert.

[¡Escucha, palomo: tienes que conseguir una muchacha, y metéselo! El tío Rudolfo tenía cuatro hijos con tres mujeres diferentes, de manera que el cabrón sin duda era el experto de metéselo gobernante de la familia.]

(Díaz 2007b/2010: 35, traducido al danés por Niels Lyngsø)

b) Hør her, palomo: Du må gripe fatt i en muchacha og stikke den inn i henne. Da ordner alt seg. Begynn med en stygg en. ¡Coje esa fea y méteselo! Grip fatt i den stygge jenta og stikk den inn i'a! Tío Rudolfo hadde fire unger med tre forskjellige damer, så fyren var utvilsomt familieresidensens stikk-den-inn-ekspert [¡Escucha, palomo: tienes que agarrar a una muchacha y méterselo! Entonces todo se arreglará. Comienza con una fea. ¡Coje esa fea y méteselo! Agarra la muchacha fea y metéselo. El tío Rudolfo tenía cuatro niños con tres mujeres diferentes, de manera que el tipo sin duda era el experto en meterlo de la residencia familiar.]

(Díaz 2007c/2010: 33-34, traducido al noruego por Hege Hammer y Henning Hagerup)

c) Hör på här, palomo: du måste få tag i en muchacha, y metéselo. Då fixar sig allting. Börja med en fea. Coje den där fean y metéselo! Tío Rudolfo hade fyra barn med tre olika kvinner så blatten var helt klart familjens metéseloexpert.

[Escucha, palomo: tienes que agarrar a una muchacha, y metéselo! Entonces todo se arreglará. Comienza con una fea. Coje aquella fea y metéselo. El tío Rudolfo tenía cuatro niños con tres mujeres diferentes, de manera que el morenito obviamente era el experto en metérselo de la familia.]

(Díaz 2007d/2010: 34-35, traducido al sueco por Niclas Hval)

En este párrafo encontramos seis elementos en español, de los que dos se repiten dos y tres veces respectivamente ( fea y metéselo). Por el contexto lingüístico, la palabra listen y el uso de la coma, un lector que no sabe español puede entender que palomo es un nombre apelativo; las palabras muchacha y fea probablemente sean conocidas por un lector escandinavo con un mínimo de conocimientos de español; tío está antepuesto a un nombre propio, de manera que se puede adivinar que es una especie de título. En cambio, los dos verbos de coje [sic] y metéselo son difíciles de entender para alguien que no sepa español, pero el segundo se puede comprender por la descripción del tío Rudolfo.

El traductor danés omite tres oraciones, entre ellas las dos que contienen la palabra fea, y transfiere el resto de las palabras en español (palomo, muchacha y metéselo) al texto danés, juntando las dos últimas palabras mediante guion. Las tres palabras se encuentran en el glosario. 
Los traductores noruegos se sirven de varias estrategias en su traducción: primero, transfieren las palabras palomo, muchacha y tío; segundo, mantienen toda una oración añadiendo su traducción ( «Coje esa fea y méteselo! Grip fatt $i$ den stygge jenta og stikk den inn i'a!) y, tercero, traducen literalmente la frase verbal: metéselo, usando la expresión coloquial dialectal i’a [en ella]. El párrafo suena quizá aún más vulgar en noruego que en español. Hay que añadir que los traductores noruegos también corrigen el español de Díaz: ponen signo de exclamación al comienzo de la oración en español y cambian la forma verbal del voseo a la forma de tuteo (méteselo).

El traductor sueco transfiere las palabras en español y, en dos ocasiones, las ajusta a la lengua sueca: en la segunda aparición de la palabra fea añade el sufijo determinativo $\underline{-\boldsymbol{n}}$ y junta las palabras expert [experto] y metéselo.

Las traducciones de este párrafo muestran bastante bien el método preferido por los traductores: el danés transfiere y explica en el glosario; los noruegos traducen, transfieren con explicaciones o traducciones y corrigen el original; y el sueco cambia lo menos posible. Es también interesante observar que ninguna de las versiones mantiene la palabra nigger del original, puesto que es considerada una palabra que no se debe usar. En danés se traduce por stodder [cabrón], palabra que, según el Den Danske Ordbog [diccionario danés], ${ }^{19}$ es despectiva y se refiere a una persona que se porta mal o es sexualmente arrogante. La versión noruega lo traduce por la palabra fyr [tío], que puede ser tanto neutra como despectiva, ${ }^{20} \mathrm{y}$ en sueco se traduce por

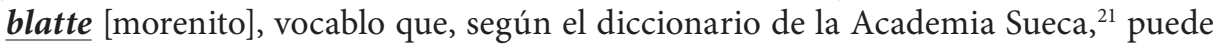
ser percibido como ofensivo y significa una persona morena de origen extranjero. Esto corresponde con lo que encuentra Boyden y Goethals en su análisis: que, hasta cierto punto, el tono racial se pierde en las traducciones al español (2011: 37).

Pasamos ahora a analizar todos los elementos en español de la primera parte de la obra. En primer lugar, se identifican todos los elementos escritos en español, sin tomar en consideración los nombres propios ni las notas a pie de página puestas por el autor. Tampoco se toma en cuenta la interferencia sintáctica entre las lenguas, es decir cuando en el inglés se usa estructuras gramaticales pertenecientes al español. Luego se identifican las estrategias utilizadas por parte de los traductores.

En total se han identificado 89 elementos escritos en español, sean referencias culturales al mundo hispano en general o al mundo caribeño o dominicano en particular, o elementos lingüísticos (palabras sueltas, expresiones u oraciones enteras) sin que necesariamente tengan una referencia específica al mundo hispano. Los elementos encontrados los hemos dividido en las siguientes cinco categorías:

- 13 elementos culturales hispanos:

a) ocho ejemplos de elementos referentes a música, religión o folklore dominicanos o caribeños (como «bachatero», «ogún», «cigüapas [sic]») y una referencia a una fiesta religiosa de todo el mundo hispano: «Semana Santa»;

b) cinco ejemplos de elementos de palabras dominicanas o caribeñas (como «parigüayo [sic]» y «bochinche»), y la palabra «urikán», que es la transcripción en español de la palabra inglesa hurricane.

- 24 elementos lingüísticos que se refieren a relaciones familiares como abuelo/a, hijo y tío/tía. Aquí también incluimos la palabra «palomo», que en este caso tiene la misma función que el uso afectivo de hijo.

- 26 elementos de (auto)descripción o de evaluación positiva o negativa. De estos, 21 son partes de una oración (como en «Packs of morena girls», Díaz 2007a: 15) y cinco son oraciones enteras (como «Tú eres guapa!», Díaz 2007a: 13). 
- Ocho elementos de exclamación de sentimientos, de los que dos son partes de una oración (como «[...] she had a habit of screaming NATAS! In the middle of homeroom», Díaz 2007a: 17) y seis son oraciones enteras (como «Muchacho del diablo!», Díaz 2007a: 13).

- 18 ejemplos de mezcla de las dos lenguas en los que un elemento de una oración se escribe en español (elemento que no entra en las categorías arriba mencionadas):

a) ocho sustantivos con sentido referencial, como pelo ("probably the only Peruvian girl on the Planet with pelo curlier tan his sister's», Díaz 2007a: 18) y lesbiana («was convinced she'd turned into a lesbiana», Díaz 2007a: 37);

b) seis verbos conjugados, como no existe («that special blend the Dominican government swears no existe», Díaz 2007a: 26), metéselo («Listen, palomo: you have to grab a muchacha, y metéselo!», Díaz 2007a: 24) y váyanse («Now váyanse», Díaz 2007a: 31);

c) cuatro ejemplos de mezcla de otras clases de palabra (como en «Manny was muy bald», Díaz 2007a: 43, y en «He didn’t care about nada that night», Díaz 2007a: 47).

La primera categoría, referencias culturales o expresiones lingüísticas dominicanas o hispanas, no es sorprendente encontrarla en una novela que versa sobre un ambiente dominicano. Las tres categorías siguientes coinciden con lo que encuentra Jiménez Carra en su análisis: el uso del español cuando se trata de determinados contextos familiares y coloquiales (Jiménez Carra 2011: 169). Estas categorías se relacionan con el contexto familiar o con expresiones coloquiales (descripciones o expresiones de sentimientos) y por lo tanto están estrechamente relacionadas con la identidad hispana o dominicana de los protagonistas (y también del autor). Al igual que Jiménez Carra (2011:172), identificamos también que la ortografía de Díaz no siempre coincide con las reglas ortográficas. La falta de signos de interrogación o exclamación al iniciarse la oración o expresión («Muchacho del diablo!», Díaz 2007a: 13), el poner la diéresis cuando no corresponde («cigüapas», Díaz 2007a: 26) y, además, encontramos la combinación de palabras españolas con inglesas: «his tío's» (Díaz 2007a: 45). En algunos casos también encontramos palabras escritas en su versión oral: «enamorao» (Díaz 2007a: 23) por enamorado. En algunas ocasiones también usa las formas verbales propias del voseo, por ejemplo en «metéselo» (Díaz 2007a: 24).

La quinta categoría en nuestro análisis es, según nuestra manera de verlo, la más interesante, puesto que aquí Díaz mezcla el inglés y el español sin que sea fácil encontrar ningún patrón en el cambio de código lingüístico. Por una parte, aparecen palabras en español que son ya tan conocidas en el mundo norteamericano que, según Jiménez Carra, han entrado en la lengua inglesa (2011: 170). Como ejemplo de ello esta autora menciona la siguiente oración que también está en la parte que aquí analizamos: «He didn’t care about nada that night» (Díaz 2007a: 47). La palabra nada es también conocida entre los escandinavos. Por otra parte, aparecen verbos conjugados (véanse los ejemplos del último apartado de la lista) que probablemente son incomprensibles para el lector no familiarizado con el español.

Mientras que las primeras cuatro categorías caracterizan a los personajes y el ambiente de la novela, la quinta categoría podría interpretarse como reflejo del bilingüismo del escritor. Es decir, una característica inherente de la literatura escrita por latinos en EE. UU., tal como lo describe Montes-Alcalá: «These writers' language choices reveal how bilingual individuals living in the hyphen -between two cultures- 
can and sometimes need to write in both languages in order to fully express themselves» (Montes-Alcalá 2012: 86). De esa manera, pensamos que los ejemplos de la categoría cinco son ejemplos que reflejan la política lingüística de Díaz: el meter palabras en español en la lengua inglesa, sin esperar hasta que estas sean admitidas por el Oxford Dictionary (sección 2.2).

A continuación tratamos las categorías una por una para ver cómo se han traducido. Los traductores pueden servirse de muchas estrategias para verter los elementos en español a otra lengua. En nuestro análisis hemos encontrado los siguientes y los hemos agrupado en cuatro estrategias principales: 1) transferir el elemento, 2) transferir el elemento añadiendo una explicación, 3) traducir el elemento y 4) omitir el elemento.

Con la primera estrategia nos referimos a trasladar un elemento en español sin traducirlo. En algunos casos se ajustan los elementos transferidos, sea para corregir la ortografía española o para ajustar una palabra a la lengua meta:

- Ajustando la ortografía: «cigüapa» (Díaz, 2007a: 26) se traduce por «ciguapa» (Días, 2007b/2010: 37 y 2007c/2010: 35), adaptando la ortografía a la estándar española.

- Añadiendo un sufijo formativo: «puta» (Díaz, 2007a: 14) se traduce por «putan» (Díaz, 2007d/2010: 25), añadiendo el sufijo formativo sueco -n.

- Juntando dos palabras: «metéselo expert» (Díaz, 2007a: 24) se traduce por «metéseloexpert» (Díaz, 2007d/2010: 35), respetando así la norma de formar palabras compuestas en sueco.

Dentro de la segunda estrategia podemos encontrar los siguientes tipos de explicaciones:

- Explicaciones en el texto mismo: «perrito» (Díaz, 2007a: 12) se traduce por «perritodansen» [el baile perrito] (Díaz, 2007c/2010: 26); «Muchacho del diablo!» (Díaz, 2007a: 13) se traduce por «iMuchacho del diablo! Satans gutt!» [Hijo de Satanás] (Díaz, 2007c/2010: 23).

- Explicaciones en el glosario: «cuero» (Díaz, 2007a: 40) se traduce por «cuero» (Díaz, 2007b/2010: 51), y se añade la siguiente explicación en el glosario: «luder, mær» [puta, zorra] (Díaz, 2007b/2010: 349).

- Explicaciones en notas finales: «cocolos» (Díaz, 2007a: 41) se traduce por «cocolos» (Díaz, 2007c/2010: 49) más nota final: «XII Afrobritiske immigranter i Den dominikanske republikk (O.a.)» [Inmigrantes afrobritánicos en la República Dominicana (N. del T.)] (Díaz, 2007c/2010: 308).

A continuación analizamos cada categoría por separado con el fin de ver las estrategias empleadas en cada una de las traducciones a las tres lenguas escandinavas.

\subsubsection{Categoría 1: elementos culturales hispanos}

De esta categoría hemos identificado trece ejemplos en total: ocho que se refieren a la cultura y cinco expresiones lingüísticas. 
CUADRO 1

Elementos culturales hispanos

\begin{tabular}{|l|c|c|c|}
\hline $\begin{array}{l}\text { Elementos en español en el texto origen } \\
\text { Estrategia }\end{array}$ & $\begin{array}{c}\text { Texto meta } \\
\text { danés }\end{array}$ & $\begin{array}{c}\text { Texto meta } \\
\text { noruego }\end{array}$ & $\begin{array}{c}\text { Texto meta } \\
\text { sueco }\end{array}$ \\
\hline Cultura (8 elementos) & 5 & 2 & 6 \\
1. Transferencia & 3 & 5 & 2 \\
2. Transferencia con explicación & 0 & 1 & 0 \\
3. Traducción & 1 & 1 & 5 \\
\hline Expresiones lingüísticas (5 elementos) & 4 & 1 & 0 \\
1. Transferencia & 0 & 3 & 0 \\
2. Transferencia con explicación & & & \\
3. Traducción & & & \\
\hline
\end{tabular}

En esta categoría vemos que las estrategias varían hasta cierto punto, y que en la versión sueca se usa sobre todo la transferencia sin explicación, mientras que en la versión danesa se usa la transferencia tanto con como sin explicación. La versión noruega es la única en la que se traducen elementos.

\subsubsection{Categoría 2: relaciones familiares}

La segunda categoría contiene elementos relacionados a la familia, y en muchos casos se usa para describir o para dirigirse a un miembro de la familia. En algunos casos también se usa en combinación con un nombre propio, por ejemplo, tío Rudolfo.

CUADRO 2

\section{Relaciones familiares}

\begin{tabular}{|l|c|c|c|}
\hline $\begin{array}{l}\text { Elementos en español en el texto origen } \\
\text { Estrategia }\end{array}$ & $\begin{array}{c}\text { Texto meta } \\
\text { danés }\end{array}$ & $\begin{array}{c}\text { Texto meta } \\
\text { noruego }\end{array}$ & $\begin{array}{c}\text { Texto meta } \\
\text { sueco }\end{array}$ \\
\hline Relaciones familiares (24 elementos) & 0 & 23 & 23 \\
1. Transferencia & 23 & 0 & 0 \\
2. Transferencia con explicación & 0 & 1 & 1 \\
3. Traducción & 1 & 0 & 0 \\
4. Omisión & & \\
\hline
\end{tabular}

Las tres versiones coinciden en la estrategia de estas palabras, puesto que, de los 24 elementos, en las tres versiones se transfieren 23. Mientras que en la versión noruega se traduce la primera aparición de abuela, en la versión sueca se traduce una aparición de abuela por un pronombre sueco, y en la versión danesa se omite un ejemplo de hijo y explican todos los elementos en el glosario.

\subsubsection{Categoría 3: elementos de descripción o evaluación}

En esta categoría se encuentran las descripciones y evaluaciones que el narrador o un personaje hace de sí mismo o de los demás personajes. 
CUADRO 3

Elementos de descripción o evaluación

\begin{tabular}{|l|c|c|c|}
\hline $\begin{array}{l}\text { Elementos en español en el texto origen } \\
\text { Estrategia }\end{array}$ & $\begin{array}{c}\text { Texto meta } \\
\text { danés }\end{array}$ & $\begin{array}{c}\text { Texto meta } \\
\text { noruego }\end{array}$ & $\begin{array}{c}\text { Texto meta } \\
\text { sueco }\end{array}$ \\
\hline Descripción o evaluación & & & \\
Oración entera (5 elementos) & 0 & 1 & 5 \\
1. Transferencia & 5 & 3 & 0 \\
2. Transferencia con explicación & 0 & 1 & 0 \\
3. Traducción & & & \\
\hline Descripción o evaluación & 6 & 0 & 20 \\
Palabras o expresiones (21 elementos) & 12 & 12 & 1 \\
1. Transferencia & 1 & 9 & 0 \\
2. Transferencia con explicación & 2 & 0 & 0 \\
3. Traducción & & & \\
4. Omisión & & & \\
\hline
\end{tabular}

Las descripciones o evaluaciones pueden ocurrir en oraciones enteras o en palabras o expresiones aisladas. En cuanto a las oraciones enteras, la versión sueca y la danesa las transfieren. La versión danesa presenta explicaciones en el glosario, pero a veces solo explica una de las palabras de la oración, como guapa, en la oración «Tú eres guapa!» (Díaz, 2007b/2010: 23). De esa manera las explicaciones son parciales. La versión noruega se sirve de varias estrategias, y una de ellas es una combinación entre la transferencia y la traducción, en la que la traducción sirve como explicación a la parte que queda en español en el texto meta. De esa manera, «Un maldito hombre» (Díaz, 2007a: 32) se traduce por «Un maldito hombre - en forbannet mann [un maldito hombre]», (Díaz, 2007c/2010: 40). En otras ocasiones, cuando en el original se repite una oración, los traductores transfieren la primera y traducen la segunda. De manera que las oraciones «Tú eres guapa! Tú eres guapa!» (Díaz, 2007a: 13) se convierten en «iTú eres guapa! Du er pen! [Tú eres guapa]» (Díaz, 2007c/2010: 40), estrategia aquí denominada transferencia con explicación. Algunas de las exclamaciones tienen signos de exclamación solo al final de la oración en el texto original, y en estos casos los traductores noruegos corrigen el original añadiendo signos al comienzo de la oración.

En lo que a las palabras o expresiones sueltas se refiere, hay veintiuna en el original. El traductor danés transfiere dieciocho, de las cuales doce llevan una explicación. Las estrategias preferidas por los traductores noruegos son la transferencia con explicación y la traducción, mientras que el traductor sueco transfiere veinte de ellas. El traductor sueco, además, muchas veces ajusta las palabras en español al sueco, añadiendo sufijos determinativos y así traduce puerca (Díaz, 2007a: 17) por puercan [la puerca], (Díaz, 2007d/2010: 28) y en esta categoría encontramos cinco ejemplos de ello.

\subsubsection{Categoría 4: exclamación de sentimientos}

El texto tiene muchos diálogos y, por tanto, también varias exclamaciones de sentimientos que hemos reunido en esta categoría. 
CUADRO 4

Exclamaciones de sentimientos

\begin{tabular}{|l|c|c|c|}
\hline $\begin{array}{l}\text { Elementos en español en el texto origen } \\
\text { Estrategia }\end{array}$ & $\begin{array}{c}\text { Texto meta } \\
\text { danés }\end{array}$ & $\begin{array}{c}\text { Texto meta } \\
\text { noruego }\end{array}$ & $\begin{array}{c}\text { Texto meta } \\
\text { sueco }\end{array}$ \\
\hline Exclamaciones & & & \\
Oraciones enteras (6 elementos) & 0 & 0 & 6 \\
1. Transferencia & 6 & 4 & 0 \\
2. Transferencia con explicación & 0 & 2 & 0 \\
3. Traducción & & & \\
\hline Palabras/Sintagmas (2 elementos) & 0 & 0 & 2 \\
1. Transferencia & 2 & 2 & 0 \\
2. Transferencia con explicación & & & \\
\hline
\end{tabular}

En esta categoría hay seis elementos de oraciones enteras que expresan sentimientos y dos elementos de palabras o sintagmas. No hay diferencia en las estrategias elegidas entre los dos grupos. El traductor danés transfiere todos los elementos, añadiendo una explicación en el glosario. Los traductores noruegos transfieren y añaden una explicación en forma de traducción en seis casos. El traductor sueco transfiere todos los elementos. Las versiones danesa y noruega explican al lector que la expresión «NATAS» (Díaz 2007a: 17) es Satán escrito al revés (Díaz 2007b/2010: 351, Díaz 2007c/2010: 27).

\subsubsection{Categoría 5: mezcla de lenguas}

En esta categoría encontramos elementos en español intercalados en el discurso inglés que no pertenecen a las categorías anteriores. Se trata de elementos lingüísticos de uso general, que no remiten a la cultura hispana ni son expresiones de evaluación o sentimientos.

\section{CUADRO 5}

\section{Mezcla de lenguas}

\begin{tabular}{|l|c|c|c|}
\hline $\begin{array}{l}\text { Elementos en español en el texto origen } \\
\text { Estrategia }\end{array}$ & $\begin{array}{c}\text { Texto meta } \\
\text { danés }\end{array}$ & $\begin{array}{c}\text { Texto meta } \\
\text { noruego }\end{array}$ & $\begin{array}{c}\text { Texto meta } \\
\text { sueco }\end{array}$ \\
\hline Verbos (6 ejemplos) & 1 & 1 & 6 \\
1. Transferencia & 3 & 3 & 0 \\
2. Transferencia con explicación & 0 & 2 & 0 \\
3. Traducción & 2 & 0 & 0 \\
4. Omisión & 1 & 2 & 8 \\
\hline Sustantivos (8 ejemplos) & 6 & 0 & 0 \\
1. Transferencia & 1 & 6 & 0 \\
2. Transferencia con explicación & 2 & & \\
3. Traducción & 2 & 3 & 4 \\
\hline Otras clases de palabras (4 ejemplos) & 0 & 0 & 0 \\
1. Transferencia & & 1 & 0 \\
2. Transferencia con explicación & & \\
3. Traducción & & & \\
\hline
\end{tabular}

En esta última categoría vemos que tanto la versión noruega como la danesa se valen de varias estrategias, mientras que el traductor sueco transfiere todas las palabras en español (en algunos casos con una adaptación a la morfología sueca). La versión noruega es la que más traducciones tiene: nueve de dieciocho ejemplos. 
Para concluir el análisis, viendo todos los ejemplos en conjunto, es obvio que la versión sueca y la danesa son las más fieles a su método general: el traductor sueco transfiere 86 de 89 casos (solamente 3 de ellos con explicación), el traductor danés transfiere 81 de 89 casos (65 de ellos con explicación en el glosario). Los traductores noruegos se valen de varias estrategias: traducen 26 elementos, en 30 casos transfieren con explicación, mientras que en 33 casos transfieren sin explicación, 23 de estos últimos se refieren al ámbito familiar. De manera que, salvo en los casos de referencia familiar, sus estrategias también corresponden a su método general: hacer los elementos en español comprensibles para los lectores, sea mediante la traducción o la explicación. La única versión que omite elementos es la danesa, que omite cinco elementos.

\section{Conclusión}

El bilingüismo de la novela $B W L O W$ es un caso interesante para ver las preferencias de los traductores a las lenguas escandinavas, puesto que los tres países escandinavos se parecen en lo que a sus lenguas y a sus culturas se refiere. Por lo tanto, no hay grandes diferencias ni lingüísticas ni culturales que impidan que se elija las mismas estrategias cuando se trata de verter los elementos en español del texto original a las lenguas meta. Todas las estrategias aquí presentadas, tanto a nivel macro como microtextual, perfectamente se podrían aplicar en los tres casos. Los métodos generales representan por lo tanto más bien una elección por parte de los traductores y/o sus editoriales.

De las tres traducciones estudiadas, la versión sueca es la versión que más fiel se mantiene al cambio de código lingüístico en la versión original, mientras que la versión noruega es la que más traduce y explica los elementos en español. De esa manera, refiriéndonos a Torres (sección 2.2) podemos decir que la versión sueca complace al lector bilingüe, mientras que la versión noruega complace al lector monolingüe. Los lectores suecos experimentan lo mismo que los lectores del original: los que no saben español probablemente se frustran o se sirven de los glosarios español-inglés que se encuentran en Internet. Los lectores noruegos son ayudados por los traductores y el bilingüismo del original hasta cierto punto desaparece. La versión danesa usa la estrategia de un glosario que, según Torres, también complace al lector monolingüe. Sin embargo, puesto que las palabras que se encuentran en el glosario no están marcadas en el texto, el lector monolingüe no necesariamente se da cuenta del glosario y el texto se presenta como bilingüe. Por consiguiente, podemos decir que la versión danesa es una traducción que complace tanto al lector bilingüe como al monolingüe. Sin embargo, en ningún momento cabe duda de que es una obra que tiene lugar en un ambiente dominicano-americano, ni que los protagonistas hablan español.

Otro aspecto que diferencia las tres traducciones es que la versión noruega corrige el español de Díaz, tanto si se trata de la ortografía como del uso de versiones dominicanas de la lengua (por ejemplo, el voseo en el verbo metéselo). Estas correcciones pueden verse desde una perspectiva didáctica: los traductores quieren que el lector se enfrente a un español estándar. O sea, que la norma de la lengua tiene preferencia ante el ser fiel al original. Esto se corresponde con lo que encontramos al comparar estos aspectos con las dos versiones traducidas al español. Ambas versiones 
en español también corrigen el español a una ortografía normativa y a un español estándar en los ejemplos aquí analizados, por ejemplo «metéselo» se traduce por «méteselo», «cigüapas», por «ciguapas», y se añaden los signos de ortografía que faltan en el original.

Podemos también concluir con que el deseo de Díaz de acelerar la introducción de vocablos en español en la lengua inglesa más rápido de lo normal se extiende también a las lenguas escandinavas, aunque esto probablemente no ha sido intención del autor.

\section{NOTAS}

1. Fresneda, Carlos (2007): Junot Díaz: Todos mis sueños son bilingües. El Mundo, 15 de octubre de 2007. Consultado el 1 de enero de 2018, <http://www.elmundo.es/elmundo/2007/10/15/ cultura/1192413539.html>.

2. DíAz, Junot (2007a): The Brief Wondrous Life of Oscar Wao. Nueva York: Riverhead Books.

3. Juarros-Daussa, Eva (2012/2014): Cambio de código. Diccionari de Lingüística. Consultado el 2 de septiembre de 2018, <http://www.ub.edu/diccionarilinguistica/content/cambio-de-c\%C3\%B3digo >.

4. Kulbrandstad, Lars Anders (2003): Minoritetsspråk og minoritetsspråksbrukere i Norge [Lenguas minoritarias y usuarios de las lenguas minoritarias en Noruega]. Consultado el 30 de junio de 2017, <http://www.sprakradet.no/Vi-og-vart/Publikasjoner/Spraaknytt/Arkivet/2003/1_2/ Minoritetsspraak/>.

5. La entrevista es de 1996, aunque se publicó en el 2000 y, por tanto, se refiere en esta cita a sus primeras obras, como Drown, de 1995.

6. Amazon.com (2008): Customer Review. Amazon.com. Consultado el 1 de enero de 2018, <http:// www.amazon.com/gp/customer-reviews/RB9CWCIFVSHXE/ref=cm_cr_pr_viewpnt?ie=UTF8\& ASIN $=1594483299 \#$ RB9CWCIFVSHXE $>$.

7. Hausman, Aliza (2008): The Oscar Wao Vocabulary Dictionary Glossary, You're Welcome, Junot Diaz. Memoirs of a Jewminicana. Aliza Hausman's Blog. Consultado el 1 de enero de 2018, $<$ https://alizahausman.com/2008/12/09/the-oscar-wao-vocabulary-dictionary-glossary-yourewelcome-junot-diaz/>.

8. Anónimo (s. f.): The Annotated Oscar Wao: Notes and translations for The Brief Wondrous Life of Oscar Wao by Junot Díaz. Consultado el 1 de enero de 2018, <http://www.annotated-oscar-wao. com>.

9. Obejas, Achy (2012): Translating Junot. Chicago Tribune. Consultado el 3 de marzo de 2018, $<$ http://www.chicagotribune.com/lifestyles/books/ct-prj-0916-book-of-the-month-20120914-story. html>.

10. EFE (2008): Junot Díaz: «Necesitamos un movimiento pro vida tranquila para volver a leer». El País. Consultado el 1 de enero de 2018, <https://elpais.com/cultura/2008/06/09/actualidad/ 1212962408_850215.html>.

11. CÉSPEDEs, Diógenes (2009): ¿Qué es la traducción para Junot Díaz? Hoy Digital. Consultado el 1 de enero de 2018, <http://hoy.com.do/que-es-la-traduccion-para-junot-diaz>.

12. Como ejemplo se pueden mencionar las novelas policíacas de Liza Marklund (escritora sueca) o de Robert Wilson (escritor británico traducido a las lenguas escandinavas). La trama de sus obras en muchos casos tiene lugar en España y ambos escritores intercalan palabras españolas en sus textos.

13. DíAz, Junot (2007b/2009/2a.ed.2010): Oscar Wao \& hans korte og forunderlige liv (traducido del inglés al danés por Niels Lyngsø). Copenhague: Gyldendal Pocket.

14. DíAz, Junot (2007c/2009/2a ed. 2010): Oscar Waos korte, makeløse liv (traducido del inglés al noruego por Hege Hammer y Henning Hagerup). Oslo: Cappelen Damm.

15. DíAz, Junot (2007d/20/2a. ed. 2010): Oscar Waos korta förunderliga liv (traducido del inglés al sueco por Niclas Hval). Estocolmo: Bonnier Pocket.

16. Hansen, Per Krogh (2009): Stakkels Oscar Wao [Pobre Oscar Wao]. Berlingske. Consultado el 1 de enero de 2018, <https://www.b.dk/boeger/stakkels-oscar-wao>.

17. Morgenbladet (2008): Årets Pulitzer-vinner har en øvre aldersgrense [El ganador del Pulitzer de este año tiene una edad límite superior]. Morgenbladet. Consultado el 1 de enero de 2018, $<$ https://morgenbladet.no/boker/2008/menneskemerket $>$. 
18. Texto noruego: «[...] men det særegne språket i boken, et sted mellom spanglish, rollespill-lingo og rap, er nok langt å foretrekke i originaltapning».

19. Den Danske Ordbog (s. f.): Stodder [cabrón]. Den Danske Ordbog [El diccionario danés]. <http:// ordnet.dk/ddo/ordbog?query=stodder $>$.

20. BoKMÅLSORDBOKA (2017): Fyr [tío]. Bokmålsordboka [Diccionario noruego]. <https://ordbok.uib. no/perl/ordbok.cgi?OPP=FYR\&ant_bokmaal=5\&ant_nynorsk=5\&bokmaal=+\&ordbok=bokmaal $>$.

21. Svenska Akademiens ordbok (2015): Blatte [morenito]. Svenska Akademiens ordbok [El diccionario de la Academia Sueca]. <https://svenska.se/tre/?sok=blatte\&pz=1>.

\section{REFERENCIAS BIBLIOGRÁFICAS}

Boyden, Michael y Goethals, Patrick (2011): Translating the Watcher's Voice: Junot Díaz's The Brief Wondrous Life of Oscar Wao into Spanish. Meta. 56(1):20-41.

Céspedes, Diógenes, Torres-Saillant, Silvio y Díaz, Junot (2000): Fiction is the Poor Man's Cinema: An Interview with Junot Díaz. Callaloo. 23(3):892-907.

Chesterman, Andrew (2004): Hypotheses about Translation Universals. In: Gyde Hansen, Kirsten Malmkjaer y Daniel Gile, eds. Claims, Changes, Challenges in Translation Studies: Selected Contributions from the EST Congress, Copenhagen 2001. Ámsterdam: John Benjamins, 1-14.

Delabastita, Dirk y Grutman, Rainier (2005): Fictional representations of multilingualism and translation. Linguistica Antverpiensia. New Series - Themes in Translation Studies. 4:11-34.

García Vizcaíno, María José (2008): Cicernos' Code-Mixed Narrative and its Implications for Translation. Mutatis Mutandis. (1)2:212-224.

Jiménez Carra, Nieves (2011): La traducción del cambio de código inglés-español en la obra The Brief Wondrous Life of Oscar Wao, de Junot Díaz. Sendebar. 22:159-180.

Jonsson, Carla (2012): Making Silenced Voices Heard: Code-switching in Multilingual Literary Texts in Sweden. In: Mark Sebba, Shahrzad Maнootian y Carla Jonsson, eds. Language Mixing and Code-Switching in Writing. Approaches to Mixed-Language Written Discourse. Londres/Nueva York: Routlegde, 212-232.

Munday, Jeremy (2007): Style and Ideology in Translation: Latin American Writing in English. Nueva York: Routledge.

Montes-Alcalá, Cecilia (2012): Code-switching in US-Latino Novels. In: Mark SebBA, Shahrzad Maноoтian y Carla Jonsson, eds. Language Mixing and Code-Switching in Writing. Approaches to Mixed-Language Written Discourse. Londres/Nueva York: Routlegde, 68-88.

TAIVALKoski, Kristiina (2002): Traduire la mixité formelle: l'exemple des premières (re)traductions de Fielding en France. Faits de langue. 19:85-97.

Torres, Lourdes (2007): In the Contact Zone: Code-Switching Strategies by Latino/a Writers. MELUS. 32(1):75-96. 